\title{
Commentary: Postconditioning of the injured spinal cord: Can we do more?
}

\author{
Oliver J. Liakopoulos, MD
}

\author{
From the Department of Cardiothoracic Surgery, Heart Center, University of Cologne, Cologne, Germany. \\ Disclosures: Author has nothing to disclose with regard to commercial support. \\ Received for publication April 28, 2019; accepted for publication April 29, 2019; available ahead of print June 22, \\ 2019. \\ Address for reprints: Oliver J. Liakopoulos, MD, Department of Cardiothoracic Surgery, Heart Center of the Uni- \\ versity of Cologne, Kerpener Strasse 62, 50924 Cologne, Germany (E-mail: oliver.liakopoulos@uk-koeln.de). \\ J Thorac Cardiovasc Surg 2020;159:827-8 \\ $0022-5223 / \$ 36.00$ \\ Copyright (C) 2019 by The American Association for Thoracic Surgery \\ https://doi.org/10.1016/j.jtcvs.2019.04.106
}

Spinal cord injury (SCI) is still one of the most devastating complications of aortic surgery. It occurs in as many as $20 \%$ of patients after open and endovascular thoracoabdominal aortic aneurysm repair and is associated with poor longterm outcomes and increased health care costs. ${ }^{1,2}$ Accumulating evidence from multicentric registry data analyzing clinical outcomes after aortic arch surgery with modern hybrid stent grafts, also known as the frozen elephant trunk (FET) procedure, suggests the occurrence of postprocedural SCI in as many as $7 \%$ of patients, thereby calling into question the deliberate use of the FET procedure. $^{3}$ SCI occurred in $6.5 \%$ of 170 patients after the FET procedure in the international, multicenter registry for the E-vita OPEN PLUS hybrid stent graft (JOTEC GmbH Hechingen, Germany). ${ }^{4}$ Similarly, a recently published article in the Journal from the International Aortic Arch Surgery Study Group reported an SCI rate of 6.3\% after the FET procedure.

The underlying mechanisms of SCI after aortic surgery are not yet fully understood. As a consequence, current therapeutic strategies largely focus on various perioperative and intraoperative measures to prevent or limit the effects of spinal cord ischemia and subsequent reperfusion injury. These measures include sufficient cooling of the core body temperature, avoidance of prolonged duration of lower body circulatory arrest, blood pressure management, cortisone application, selective antegrade cerebral perfusion, and continuous cerebrospinal fluid drainage. ${ }^{6-8}$ Furthermore, surgical strategies mainly have the target of preserving collateral blood supply to the spinal cord. Avoidance of extended stent coverage of aortic segments or the left subclavian artery, reinsertion of the segmental artery in thoracoabdominal aortic aneurysm repair, and achievement of an optimal distal landing zone (higher than $\mathrm{T} 7$ to T10) during the FET procedure have all been linked to a decrease in the incidence of SCI. ${ }^{3,7,8}$ The introduction of the spinal cord collateral network concept by Griepp and coworkers ${ }^{9,10}$ and its recent clinical translation of preconditioning the paraspinal arterial

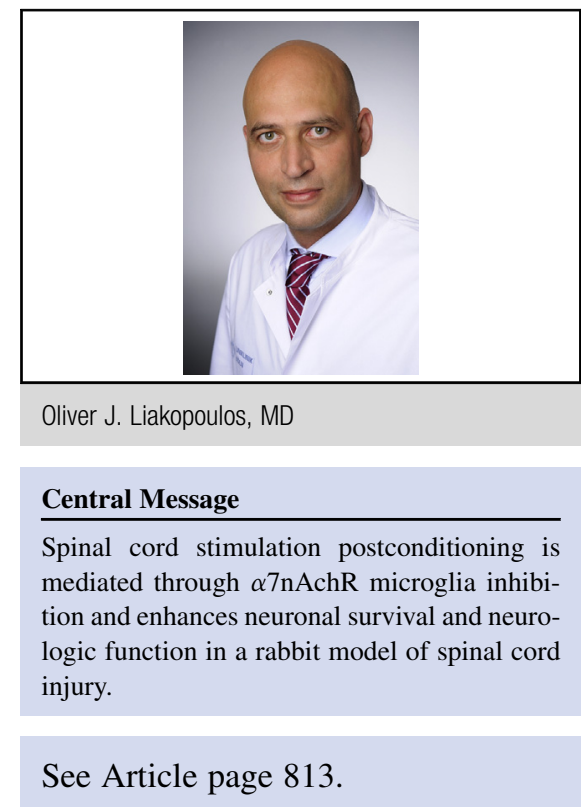

collateral network perfusion system by minimally invasive selective segmental artery coil embolization before thoracoabdominal aortic aneurysm repair ${ }^{11}$ represent another important step toward decreasing SCI in this high-risk patient cohort.

This issue of the Journal presents the results of a very interesting basic science report by $\mathrm{Li}$ and coworkers ${ }^{12}$ that adds another important piece in the puzzle of understanding the underlying mechanisms of delayed SCI after aortic surgery. $\mathrm{Li}$ and coworkers ${ }^{12}$ focused on the postconditioning effects of spinal cord stimulation (SCS) in a rabbit model of transient spinal cord ischemia triggered by a balloon occlusion of the infrarenal aorta for 28 minutes with subsequent reperfusion. Spinal cord stimulation $(2 \mathrm{~Hz}$ for 30 minutes through an epidural electrode) at the onset of reperfusion and then daily for 1 week attenuated ischemiareperfusion injury by inhibition of proinflammatory microglia activation, enhancing neuronal survival and neurologic function of the spinal cord. Most importantly, Li and coworkers $^{12}$ found that the neuroprotective effects of SCS in delayed SCI were mediated through $\alpha 7$ nicotinic acetylcholine receptor $(\alpha 7 \mathrm{nAchR})$ microglia inhibition. This finding was supported by the fact that the aforementioned positive neuroprotective effects of SCS were largely blunted in animals that received serial subarachnoid injections of a selective irreversible $\alpha 7 \mathrm{nAchR}$ antagonist. 
$\mathrm{Li}$ and coworkers ${ }^{12}$ are to be congratulated for their excellent basic research work on this highly complex and clinically relevant topic. They have elucidated a relevant mechanism of SCI in complex aortic surgery and potentially provided a target for future pharmacologic therapies that specifically target microglia inhibition through $\alpha 7$ nAchR agonists. Although it may be premature to reach a final conclusion for clinical practice on the basis of this experimental work, it seems intriguing to speculate that a therapeutic combination of spinal cord preconditioning and postconditioning (including minimally invasive selective segmental artery coil embolization, SCS, or $\alpha 7 \mathrm{nAchR}$ agonists) may diminish SCI and its detrimental clinical sequelae for patients undergoing surgery for complex aortic disease. Further experimental evidence is needed, perhaps from larger animal models, under conditions that more closely reflect the clinical setting of extensive aortic repair (including longer durations of thoracoabdominal spinal cord ischemia, persisting malperfusion, and postreperfusion treatment regimen) to confirm the promising results of this excellent work.

\section{References}

1. Bicknell CD, Riga CV, Wolfe JH. Prevention of paraplegia during thoracoabdominal aortic aneurysm repair. Eur J Vasc Endovasc Surg. 2009;37:654-60.

2. Huynh TT, Miller CC III, Estrera AL, Sheinbaum R, Allen SJ, Safi HJ. Determinants of hospital length of stay after thoracoabdominal aortic aneurysm repair. $J$ Vasc Surg. 2002;35:648-53.

3. Shrestha M, Bachet J, Bavaria J, Bavaria J, Carrel TP, De Paulis R, et al. Current status and recommendations for use of the frozen elephant trunk technique: a position paper by the vascular domain of EACTS. Eur J Cardiothorac Surg. 2015;47:759-69.

4. Leontyev S, Tsagakis K, Pacini D, Di Bartolomeo R, Mohr FW, Weiss G, et al. Impact of clinical factors and surgical techniques on early outcome of patients treated with frozen elephant trunk technique by using EVITA open stent-graft: results of a multicentre study. Eur J Cardiothorac Surg. 2016;49:660-6.

5. Poon SS, Tian DH, Yan T, Harrington D, Nawaytou O, Kuduvalli M, et al; International Aortic Arch Surgery Study Group (IASSG). Frozen elephant trunk does not increase incidence of paraplegia in patients with acute type A aortic dissections. J Thorac Cardiovasc Surg. April 14, 2019 [Epub ahead of print].

6. Haldenwang PL, Häuser L, Prochnow N, Ziebura D, Baumann A, Sikole M, et al. Low-flow lower body perfusion for spinal protection in a frozen elephant trunk simulation model. Eur J Cardiothorac Surg. 2016;50:963-70.

7. Leontyev S, Dieterlen MT, Halling M, Schlegel F, Hoyer A, Ossmann S, et al. Evaluation of conventional and frozen elephant trunk techniques on spinal cord blood flow in an animal model. Eur J Cardiothorac Surg. 2017;52:485-91.

8. Grabenwöger M, Alfonso F, Bachet J, Bonser R, Czerny M, Eggebrecht H, et al European Association for Cardio-Thoracic Surgery (EACTS), European Society of Cardiology (ESC), European Association of Percutaneous Cardiovascular Interventions (EAPCI). Thoracic endovascular aortic repair (TEVAR) for the treatment of aortic diseases: a position statement from the European Association for Cardio-Thoracic Surgery (EACTS) and the European Society of Cardiology (ESC), in collaboration with the European Association of Percutaneous Cardiovascular Interventions (EAPCI). Eur J Cardiothorac Surg. 2012;42:17-24.

9. Griepp RB, Griepp EB. Spinal cord perfusion and protection during descending thoracic and thoracoabdominal aortic surgery: the collateral network concept. Ann Thorac Surg. 2007;83(Suppl):S865-9; discussion S890-2.

10. Etz CD, Kari FA, Mueller CS, Brenner RM, Lin HM, Griepp RB. The collateral network concept: remodeling of the arterial collateral network after experimental segmental artery sacrifice. J Thorac Cardiovasc Surg. 2011;141: 1029-36.

11. Etz CD, Debus ES, Mohr WF, Köbel T. First in man endovascular preconditioning of the paraspinal collateral network by segmental artery coil embolization to prevent ischemic spinal cord injury. J Thorac Cardiovasc Surg. 2015;149: 1074-9.

12. Li H, Dong X, Cheng W, Jin M, Zheng D. Neuroprotective mechanism involved in spinal cord stimulation postconditioning neuroprotective effects of spinal cord stimulation postconditioning. J Thorac Cardiovasc Surg. 2020;159:813-24.e1. 